\title{
De verbos de colocación a pseudo-copulativos: procesos de gramaticalización en los cuasi-sinónimos poner/meter y pôr/meter en español y en portugués.
}

\author{
MARIE COMER, RENATA ENGHELS y CLARA VANDERSCHUEREN
}

\section{Abstract}

Most studies on locative verbs focus on (a) the internal organization of this verbal category and its position within various verb classifications, (b) the syntactic analysis of their arguments, and more particularly the status of the locative complement. The aim of the present paper is to compare the syntax and semantics of the frequently used locative verbs poner and meter $_{\text {esp }}$ in Spanish with their Portuguese cognate counterparts pôr and meter ${ }_{p t g}$. We examine to what extent the use of these near-synonyms goes beyond the basic locative meaning and extends towards other, more grammaticalized, domains. More particularly, on the basis of translation corpus data and comparable corpus data, we empirically analyze the semantic features of their transfer use, their causative/incoative uses and their (pseudo)copulative uses, and we shed light on their frequencies. It will be shown that the Spanish verbs present a higher degree of grammaticalization compared to their Portuguese counterparts, and that intralinguistically, poner and pôr are far more grammaticalized than their near-synonyms meter $_{\text {esp }} /$ meter $_{\text {ptg }}$.

Keywords: locative verbs, poner/meter, pôr/meter, corpus linguistics, grammaticalization, Romance languages

\section{Introducción}

El presente artículo se dedica a un análisis semántico contrastivo de los verbos de colocación poner y meter en español y sus homólogos portugueses pôr y meter. La investigación sobre esta categoría verbal suele concentrarse (i) en su organización interna, (ii) en su clasificación dentro de las diversas tipologías verbales más generales (cf. Boons 1987, Dixon 1991, Guillet \& Leclère 1992, Levin 1993, Crego García 2000, Cifuentes Honrubia \& Llopis Ganga 2000, entre otros) y (iii) en el estatuto sintáctico de sus diferentes argumentos, particularmente con respecto al complemento de lugar (cf. Guillet \& Leclère 1992: 123-124, Cuartero Otal 2003: 137-138, Cifuentes 2004: 74,76). ${ }^{1}$

Desde un punto de vista semántico, el proceso locativo prototípico presenta un objeto que sufre un cambio de lugar, desplazándose de un lugar de origen a otro lugar de destino. Según Talmy (1985: 62), el proceso de localización se compone de cinco constituyentes semánticos:

\footnotetext{
${ }^{1}$ Sintácticamente, los verbos de colocación de tipo poner, meter, colocar, ubicar, etc. presentan una estructura argumental trivalencial (Guillet \& Leclère 1992): $[\mathrm{S}+\mathrm{V}+\mathrm{OD}+$ Compl. de lugar $]$. La terminología del complemento de lugar ha sido objeto de discusión. Así, los proponentes del término "complemento adverbial" (p.ej. Rojo 1985) se oponen a los alarquianos, quienes prefieren hablar de "suplemento inherente" (Alarcos 1990). En este artículo no nos detendremos en este debate, por lo que utilizaremos el término general "complemento de lugar".
} 
(i) una figura o entidad desplazada, (ii) una base o un fondo respecto al cual la figura se mueve, (iii) un rasgo de movimiento expresado por el verbo, (iv) la dirección ${ }^{2}$ y (v) un componente facultativo de manera o causa. Los verbos locativos poner/pôr y meter esp/ptg únicamente transmiten informaciones sobre la posición final del objeto desplazado, y no sobre su posición inicial. Se caracterizan, pues, siempre por una polaridad final (Boons 1987), contrariamente a verbos como quitar y extraer [un diente de la boca], que focalizan más bien la posición inicial.

Tal caracterización sugiere que los miembros de los binomios poner/meter esp y pôr/meter $_{\text {ptg }}$ se conmuten libremente: ponerse/meterse en la cola de una fila, pôr/meter os livros na gaveta. Sin embargo, en otros contextos solo uno de los verbos parece acertado: El río se mete en el mar vs. *El río se pone en el mar; poner los platos sobre la mesa vs. *meter los platos sobre la mesa; pôr as cartas sobre a mesa vs. *meter as cartas sobre a mesa. ${ }^{3}$ Así, al limitarse su conmutabilidad a determinados contextos, los binomios entran en ambas lenguas en una relación de cuasi-sinonimia. ${ }^{4}$

Algunos estudios anteriores que tratan esta oposición cuasi-sinónima (Cifuentes Honrubia \& Llopis Ganga 1996, 2000; Cifuentes Honrubia 2004; Crego García 2000), ya determinaron diferencias importantes entre el uso locativo de poner y meter en español, y clasificaron ambos verbos dentro de clases verbales distintas. Así, la principal distinción entre ellos residiría en el rasgo de dirección: como verbo direccional, meter $_{\text {esp }}$ implica desplazamiento generalmente hacia el interior de una entidad, mientras que poner como verbo estativo/posicional no indica dirección fija (cf. Cifuentes Honrubia \& Llopis Ganga 1996: 103,139; Cifuentes Honrubia 2004: 81-82). Si bien estas clasificaciones ya permiten explicar diversos casos de falta de equivalencia entre los miembros cuasi-sinónimos españoles (p.ej. cf. supra 'se mete en el mar' expresa dirección interior), surge una serie de preguntas.

En primer lugar, los estudios analizaron las diferencias semánticas entre poner y meter ${ }_{\text {esp }}$ principalmente desde una perspectiva española. En el presente artículo, sin embargo, no pretendemos centrarnos en las diferencias existentes entre los cuasi-sinónimos dentro de una lengua, sino que nos focalizaremos en el aspecto contrastivo e interlingüístico. En cambio, intentaremos determinar con más precisión el grado de correspondencia mutua entre

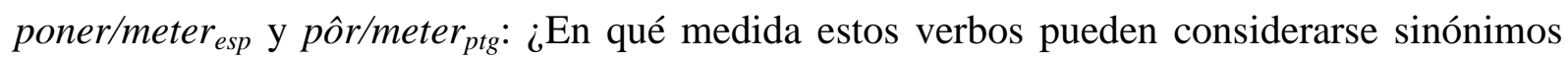
perfectos entre ambas lenguas? Efectivamente, los miembros español y portugués de ambos binomios son morfológicamente cognados y derivan de los mismos étimos latinos,

\footnotetext{
${ }^{2}$ El español se define como "verb-framed language" (Talmy 1991: 486-489), y suele incorporar informaciones sobre la dirección del movimiento en el verbo mismo (p.ej. entrar 'go in', bajar 'go down'). Sin embargo, a veces la dirección se expresa también por medio de satélites o elementos externos al verbo (p.ej. correr abajo 'run down') (Slobin 1996: 214). En el dominio de los verbos de colocación, la dirección tampoco se manifiesta siempre en el verbo: el significado inherente de p.ej. poner o ubicar no da indicaciones específicas sobre la dirección del desplazamiento.

${ }^{3}$ Se pone en la cola ofrece 1100000 resultados de búsqueda en Google, y se mete en la cola 2 360 000; pôr na gaveta da 208000 resultados, y meter na gaveta 148000 resultados; El río se mete en el mar ofrece 182000 resultados de búsqueda en Google, pero El río se pone en el mar ninguno. Lo mismo vale para poner los platos sobre la mesa (3530 resultados) y pôr as cartas sobre a mesa (5370 resultados) que se oponen a meter los platos sobre la mesa (0 resultados), y meter as cartas sobre a mesa (0 resultados). [consulta: 20/02/2013]

${ }^{4}$ La noción de cuasi-sinonimia (también conocida como 'parasinonimia', Rodríguez-Piñero Alcalá 2004) denota la relación léxica entre vocablos que tienen significados muy afines, sin ser sinónimos absolutos. Este fenómeno semántico ha sido estudiado sobre todo desde una perspectiva intralingüística (p.ej. Divjak 2010) y raramente entre lenguas diferentes (una excepción la constituye por ejemplo Enghels/Jansegers 2013).
} 
respectivamente pōnere ('colocar') y mîttere ('enviar') (Corominas 1987: 468, 394). Aparte de esta correspondencia etimológica y morfológica, es necesario comprobar en qué medida se pueden considerar como cuasi-sinónimos interlingüísticos.

En segundo lugar, los análisis citados se basan principalmente en el uso locativo básico para distinguir entre poner y meter $_{\text {esp }}$. En este artículo, nos preguntamos en qué medida se observan diferencias fuera del dominio estrictamente locativo. La literatura existente parece pasar por alto que el perfil semántico y sintáctico de poner y meter $e_{e s p}$ es bastante más complicado y sobrepasa los límites de la categoría léxica de la colocación. Así, por un proceso de gramaticalización, ${ }^{5}$ se observan extensiones semánticas del uso locativo básico hacia el campo de la atribución o la transferencia de posesión, así como a usos pseudo-copulativos, causativos e incoativos. El segundo objetivo de la presente investigación consiste, pues, en averiguar si se observan dichos usos en ambas lenguas estudiadas, y en qué medida los resultados confirman una jerarquía de gramaticalización entre las lenguas románicas, establecida por varios autores, según la cual el portugués presenta un grado de gramaticalización más bajo que el español para determinados fenómenos gramaticales (p.ej. Fagard/Mardale 2012 y Soares da Silva 2012, entre otros).

De acuerdo con estas metas, el estudio se desarrollará en tres fases. En la sección 2 propondremos una descripción más detallada de la polisemia de los cuatro lexemas. El inventario de los diferentes núcleos semánticos posibles dará una primera indicación en cuanto al grado de correspondencia de poner/meter ${ }_{\text {esp }}$ y pôr/meter ${ }_{\text {ptg. }}$. La sección 3 se dedicará a un estudio de caso, basado en un corpus paralelo de traducciones. Este estudio nos permite obtener una imagen más detallada del grado de similitud entre los verbos para verificar si se utilizan en los mismos contextos semánticos. Finalmente, en la sección 4 expondremos los resultados del análisis de un corpus comparable. Se echará luz sobre la frecuencia relativa porcentual de los distintos usos y significados distinguidos para cada verbo estudiado. Asimismo, efectuaremos un análisis multifactorial para determinar los rasgos semánticos de los distintos argumentos que requieren los verbos según el uso, con el fin de obtener una visión más clara de su comportamiento. Por último, el análisis nos permitirá determinar en qué medida los procesos de gramaticalización observados son comparables en ambas lenguas iberorromances.

\section{De verbo de colocación a verbo pseudo-copulativo}

Antes de pasar a un análisis más detenido del uso de los verbos en un corpus de textos reales, conviene echar luz sobre la intrincada semántica de los cuatro lexemas en cuestión. Si bien la presente investigación no adopta una perspectiva lexicográfica, presentamos primero un estudio de siete diccionarios. ${ }^{6}$ Este análisis lexicográfico constituye el primer paso hacia la

\footnotetext{
${ }^{5}$ Este fenómeno muy estudiado puede definirse de la manera siguiente: "Se suele llamar gramaticalización al proceso histórico por el que algunos signos léxicos de significado pleno y uso autónomo asumen valor gramatical en determinadas construcciones sintácticas, y, en general, gramaticales" RAE (2009: 2107). Ver también otras muchas referencias, entre las cuales Cuenca \& Hilferty (1999) y Garachana Camarero (1999).

${ }^{6}$ Se trata de las obras siguientes: Diccionario de construcción y régimen de la lengua castellana [DCR.], Clave: diccionario de uso del español actual [CL], Diccionario de uso del español [DUE], Diccionario del español actual [DEA], Grande Dicionário da Língua Portuguesa [GDLP], Dicionário da Língua Portuguesa Contemporânea da Academia das Ciências de Lisboa [DLP], Dicionário Houaiss da Língua Portuguesa [DH]. Véase la bibliografía para más información.
} 



primera vista, los diccionarios ofrecen un extenso inventario de las acepciones existentes, sin distinguir realmente entre significados mayores y menores, y sin explicitar las relaciones entre los significados. Sin embargo, se destacan cuatro grandes núcleos semánticos: (i) el significado locativo básico, (ii) el significado de transferencia, (iii) el significado causativo e incoativo y (iv) el significado de cambio de estado. ${ }^{7}$

En su acepción más elemental, poner/meter esp $_{\text {y }}$ pôr/meter ${ }_{p t g}$ se usan como verbo locativo: denotan un un desplazamiento. La prominencia cognitiva de este significado se confirma por ser siempre el primer uso señalado. Prototípicamente, el uso locativo evoca los siguientes argumentos: un participante humano $\mathrm{P}_{1}$ transfiere un $\mathrm{P}_{2}$ inanimado concreto a una base o a un lugar inanimado concreto (1a-1d). ${ }^{8}$

(1a) $[\text { Alguien }]_{\mathrm{P} 1}$ pone $[\mathrm{sal}]_{\mathrm{P} 2}$ [en la comida $]_{\mathrm{loc}} .(\mathrm{DUE})^{9}$

(1b) $[\text { Alguien }]_{\mathrm{P} 1}$ mete $[\text { aire }]_{\mathrm{P} 2}$ [en un balón $]_{\mathrm{loc}}$. (DUE)

(1c) $[\text { Alguém }]_{\mathrm{P} 1}$ põe $[\text { açúcar }]_{\mathrm{P} 2}$ [no leite $]_{\mathrm{loc}}$. (DLP)

(1d) $[\text { Alguém }]_{\mathrm{P} 1}$ mete $[\mathrm{a} \text { loiça }]_{\mathrm{P} 2}[\text { na máquina }]_{\mathrm{loc}}$. (DLP)

En segundo lugar, la semántica de poner/meter $_{\text {esp }}$ y pôr/meter ${ }_{p t g}$ se extiende hacia el campo de la transferencia: un participante humano $\mathrm{P}_{1}$ transfiere un ente inanimado concreto $\left(\mathrm{P}_{2}\right)$ a un beneficiario humano $\mathrm{P}_{3}$ :

(2a) $[\text { Los Reyes Magos }]_{\mathrm{P} 1}[\text { te }]_{\mathrm{P} 3}$ pusieron $[\text { tantas cositas }]_{\mathrm{P} 2}$. (DEA)

(2b) $[\mathrm{El} \text { frutero }]_{\mathrm{P} 1}[\mathrm{me}]_{\mathrm{P} 3}$ ha metido [unas manzanas podridas $]_{\mathrm{P} 2}$. (DUE)

(2c) $P o ̂ s$ [boa parte da sua fortuna $]_{\mathrm{P} 2}$ [a uma sobrinha $]_{\mathrm{P} 3}$. (DH) ${ }^{10}$

Luego, los verbos estudiados pueden adquirir un significado causativo cuando aparecen con un infinitivo precedido de la preposición $a$, en configuraciones de tipo $[\mathrm{S}+\mathrm{V}+\mathrm{OD}+a+$ infinitivo]. Semánticamente, este uso causativo implica dos participantes: un $\mathrm{P}_{1}$ agente provoca que un $\mathrm{P}_{2}$ haga o efectúe algo:

(3a) Pongo [la leche $]_{\mathrm{P} 2}$ a calentar. (DUE)

(3b) Meto [a alguien $]_{\mathrm{P} 2}$ a trabajar. (DUE)

(3c) Meteram [mulheres $]_{\mathrm{P} 2}$ a britar e a lavar o volfrâmio. (GDLP)

(3d) $P u$-[lo $]_{\mathrm{P} 2}$ a rir com minha história. (DH)

Cuando estos verbos seguidos de un infinitivo aparecen bajo su forma reflexiva - y cuando por consiguiente un solo participante entra en escena - adquieren un significado más bien incoativo:

(3e) $[\mathrm{Se}]_{\mathrm{P} 1 \text { refl }}$ metió a bailar. (DEA)

(3f) $[\mathrm{Se}]_{\mathrm{P} 1 \text { refl }}$ puso a llorar. (DCR)

(3g) Às tantas põe-[se $]_{\mathrm{P} 1 \text { refl }}$ a chover. (DLP)

\footnotetext{
${ }^{7}$ Aparte de los cuatro grandes ejes semánticos señalados, los verbos estudiados figuran también en diversas expresiones fijas, tales como poner la mesa, meter la pata, meter a saco, etc. En este artículo no tendremos en cuenta esta amplia gama de locuciones.

${ }^{8}$ El prototipo que proponemos para cada uno uso no presenta necesariamente la frecuencia de uso más elevada, sino que resulta siempre el modelo más saliente cognitivamente (de acuerdo con Kleiber 1990). Además, en este caso, el prototipo del uso locativo con $\mathrm{P}_{1}$ humano, $\mathrm{P}_{2}$ inanimado concreto y una base inanimada concreta surge en cada diccionario como primer ejemplo citado. En lo que sigue utilizaremos las abreviaciones $\mathrm{P}_{1}, \mathrm{P}_{2}$ y $\mathrm{P}_{3}$ para referir a los tres argumentos principales que pueden realizarse sintácticamente con los verbos estudiados.

${ }^{9}$ Ejemplos adaptados de casos señalados en las obras lexicográficas.

${ }^{10}$ Los diccionarios consultados no señalan ejemplos de una transferencia prototípica con meter $_{p t g}$.
} 
(3h) Apesar do desconhecimento, meteu-[se $]_{\mathrm{Pl} \text { refl }}$ a falar inglês. (DH)

Por último, el cuarto núcleo semántico lo constituyen los usos en que poner/meter esp y pôr/meter $_{\text {ptg }}$ se emplean en construcciones predicativas. En (4a/4b), dos participantes humanos entran en escena: un $\mathrm{P}_{1}$ causa que un $\mathrm{P}_{2}$ cambie de estado. En estos ejemplos se trata claramente de usos predicativos de objeto; los casos 4c/4d) ilustran el uso predicativo de sujeto. En estos casos, el verbo funciona como pseudo-cópula (RAE 2009: 2834), que marca en el plano aspectual el ingreso en otro estado de un participante típicamente humano:

(4a) $[\text { Esta medicina }]_{\mathrm{P} 1}[\mathrm{me}]_{\mathrm{P} 2}$ ha puesto $[\text { bueno }]_{\mathrm{pred.obj}}$ (DUE)

(4b) Meto [a alguien $]_{\mathrm{P} 2}[\text { de carpintero }]_{\text {pred obj. }}$ (DUE)

(4c) Espero que $[t e]_{\mathrm{P} 1 \text { refl }}$ ponhas $[\mathrm{bom}]_{\text {pred.suj. }}$ depressa. (DLP)

(4d) $[\text { A menina }]_{\mathrm{P} 1}[\mathrm{se}]_{\mathrm{P} 1 \text { refl }}$ mete $[\text { freira }]_{\mathrm{pred.suj}}$. (GDLP)

En fin, el estudio lexicográfico que acabamos de presentar da indicios de un grado de correspondencia muy elevado entre los verbos estudiados. Además, los cuatro núcleos están interrelacionados y parecen compartir el sema de 'cambio': una entidad - ya sea humana o no -, hace que cambie la posición, la pertenencia o el estado de otra entidad. Sin embargo, un análisis lexicográfico de índole esencialmente introspectiva no permite 'medir' el grado de similitud entre los cuatro verbos ni el aspecto prototípico de los significados destacados. ¿En qué medida estos núcleos semánticos aparecen en español y en portugués? ¿En qué medida los cuatro verbos conocen campos operativos idénticos y se emplean con igual frecuencia?

Trataremos de contestar a estas preguntas a partir de dos estudios de caso basados en usos concretos. Efectivamente, en las décadas más recientes, la lingüística en general y la lingüística contrastiva en particular han conocido un movimiento de aproximaciones intuitivas hacia métodos más empíricos. Al mismo tiempo, aunque predomina el uso de corpus comparables y monolingües, los corpus paralelos empiezan a ganar importancia en el campo de la lingüística contrastiva (Geeraerts 2010). El estudio de caso presentado en el apartado siguiente se basa precisamente en un tal corpus paralelo o de traducciones.

\section{Estudio de caso 1: ¿Correspondencia mutua en un corpus paralelo?}

\subsection{Metodología}

Varios autores (Aijmer \& Altenberg 1996; Altenberg \& Granger 2002) abogan por el uso de corpus paralelos dentro del ámbito de las investigaciones lingüísticas, dado que le ofrece al lingüista la posibilidad de determinar con más precisión el grado de correspondencia mutua entre unidades linguiísticas. Así, un corpus con ocurrencias de poner/meter esp $_{\text {y }}$ pôr/meter ptg $_{\text {y }}$ sus traducciones nos permitirá comprobar en qué medida el español y el portugués recurren a los mismos verbos en contextos semánticos idénticos. Además, las traducciones muestran "alternative ways of rendering a particular meaning or function in the target language" ['maneras alternativas de reproducir un significado o una función particular en la lengua meta'] (Altenberg \& Granger 2002: 9). Así pues, un estudio de traducciones se revela útil para descubrir en qué medida el español y el portugués tienden a privilegiar otros verbos equivalentes en las traducciones de cada uso, y cuáles son precisamente los equivalentes.

Sin embargo, el uso de corpus paralelos para la investigación lingüística no siempre ha gozado de aceptación unánime. Así, Gellerstam (1996), Noël (2003) y otros han señalado el 
riesgo de interferencia lingüística, peyorativamente calificado de translationese (Gellerstam 1996: 54). Al traducir una obra a su lengua materna, el traductor puede ser influenciado consciente o inconscientemente por la lengua del texto fuente (Van Hoeke \& Goyens 1990: 124). Este fenómeno resulta particularmente frecuente entre lenguas hermanas como el español y el portugués (Enghels \& Jansegers 2013; Vanderschueren 2010: 95). Además, la similitud morfológica entre los verbos de la presente investigación podría aumentar aún más el riesgo de influencias encubiertas de la lengua fuente en la lengua meta.

Para limitar al máximo estas interferencias, el estudio actual se basa en un corpus manualmente compuesto de las traducciones en español (Lengua Meta 1) y en portugués (Lengua Meta 2) de siete textos fuente, escritos en una tercera lengua, a saber el inglés ${ }^{11}$ (Texto Fuente). A este corpus aplicamos un análisis bidireccional, y más concretamente un 'Análisis de Correspondencia de Traducción Mutua' ("Mutual Translation Correspondence Analysis", Enghels \& Jansegers, 2013: 965-966), que contestará las siguientes preguntas:

Cuando $\mathrm{LM}_{1}$ traduce el contenido semántico del texto fuente por el verbo meter $_{\text {esp }} \mathrm{o}$ poner, ¿cuáles son los correspondientes en $\mathrm{LM}_{2}$ ? Y al revés, cuando $\mathrm{LM}_{2}$ traduce el contexto semántico de la fuente por meter $_{p t g}$ o pôr, ¿cuáles son los recursos utilizados en $\mathrm{LM}_{1}$ ?

Concretamente extraemos todas las ocurrencias de poner y meter $_{\text {esp }}$ del corpus de traducciones españolas y las hacemos corresponder con sus equivalentes en las traducciones portuguesas, y al revés: partiendo de las frases portuguesas, analizamos las ocurrencias de pôr/meter $p_{\text {tg }}$ y la traducción española correspondiente.

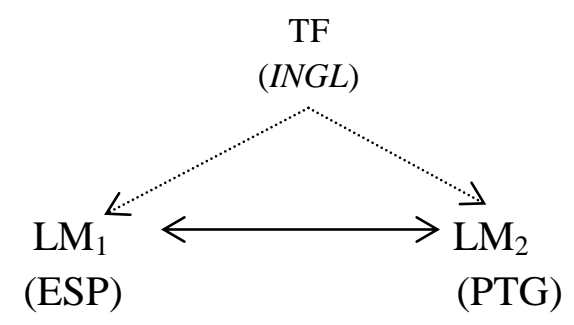

Figura 1. Composición del corpus paralelo

\subsection{Resultados y discusión}

La extracción de los casos pertinentes genera un corpus de 3542 ocurrencias de los cuatro verbos estudiados: 2213 en español y 1330 en portugués. Estos datos nos ofrecen una primera imagen de la extensión del uso de los verbos, que parece ser más amplia en español que en portugués. ¿Será que en esta lengua el uso de los verbos es más restringido y su campo de aplicación más limitado?

La tabla 1 ofrece un resumen cuantitativo del grado de correspondencia entre ambos binomios desde una perspectiva interlingüística.

\footnotetext{
${ }^{11}$ Para más datos sobre el corpus, cf. Bibliografía.
} 


\begin{tabular}{|c|c|c|c|c|c|c|c|c|}
\hline & \multicolumn{2}{|l|}{ poner } & \multicolumn{2}{|c|}{ meter $_{\text {esp }}$} & \multicolumn{2}{|l|}{ pôr } & \multicolumn{2}{|c|}{ meter $_{\text {ptg }}$} \\
\hline & $\#$ & $\%$ & $\#$ & $\%$ & $\#$ & $\%$ & $\#$ & $\%$ \\
\hline pôr & 335 & 19.3 & 16 & 3.3 & & & & \\
\hline meter $_{\text {ptg }}$ & 19 & 1,1 & 101 & 21.1 & & & & \\
\hline correspondencia cero & 1379 & 79.6 & 363 & 75.6 & & & & \\
\hline total & 1733 & 100 & 480 & 100 & & & & \\
\hline poner & & & & & 335 & 32.8 & 19 & 6.1 \\
\hline meter $_{\text {esp }}$ & & & & & 16 & 1.6 & 101 & 32.6 \\
\hline correspondencia cero & & & & & 669 & 65.6 & 190 & 61.3 \\
\hline total & & & & & 1020 & 100 & 310 & 100 \\
\hline
\end{tabular}

Tabla 1: Equivalencias interlingüísticas

Resulta claro que en general dominan los casos de 'correspondencia cero' (Salkie 2002): son los casos donde, en la traducción correspondiente en la segunda lengua se recurre frecuentemente a lexemas diferentes dentro del mismo campo semántico (5a-5b), a otras expresiones (6a-6b), o el verbo simplemente no se traduce (7a-7b):

(5a) Se volvió a la clase en general y alcanzó el tarro para coger la siguiente araña y ponerla sobre la mesa. (HPCF-ESP: 105)

(5b) Voltando-se para toda a turma procurou no pote outra aranha e colocou-a em cima da secretária. (HPCF-PTG: 178)

(6a) Hermione, métetelo en la cabeza - la interrumpió Ron, ¡A ellos les gusta la esclavitud! (HPCFESP: 111)

(6b) Hermione, abre os olhos - disse Ron bem alto. - Eles gostam, gostam de ser escravos. (HPCFPTG: 182)

(7a) ¿Por qué no te pones de nuevo esa magnífica capa y te vas a la cama? (HPPF-ESP: 212)

(7b) Agora, porque não vais dormir um pouco? (HPPF-PTG: 118)

De los cuatro núcleos semánticos deslindados en la sección anterior (cf. supra sección 2), es precisamente el uso causativo/incoativo que presenta el mayor número de casos de 'correspondencia cero' (en el $96.4 \%$ o 217/225 de los casos). Este porcentaje tan elevado se explica por la inclinación del español a no traducir el aspecto incoativo mediante los verbos poner y meter en oraciones en que el portugués suele recurrir a pôr-se + inf:

(8a) Sirius e Lupin puseram-se a rir. (HPOF-PTG: 572)

(8b) Sirius y Lupin se rieron. (HPOF-ESP: 352)

(9a) Todos os examinadores se puseram a observá-lo. (HPOF-PTG: 612-613)

(9b) Todos los examinadores observaron sus progresos. (HPOF-ESP: 377)

Además, la pseudo-cópula ponerse en su uso predicativo se traduce sistemáticamente por ficar en portugués, sobre todo cuando funciona como verbo de cambio de estado (en el $50 \%$ o 89/178 de los casos observados):

(10a) Ron se puso rojo como un tomate. (HPPA-ESP: 60)

(10b) Ron ficou vermelho como um pimentão. (HPPA-PTG: 104)

Así pues, el grado de correspondencia mutua entre poner/pôr y meter $_{\text {esp }} /$ meter $_{\text {ptg }}$ puede ser influenciado por varios factores: a menudo ambas lenguas muestran preferencias marcadas por otros verbos u otras estrategias de traducción, que difieren según el núcleo semántico y según la elección individual del traductor. 
Haciendo abstracción de los casos de correspondencia cero y focalizándonos en los contextos de equivalencia mutua entre poner/meter ${ }_{\text {esp }}$ y pôr/meter ${ }_{\text {ptg }}$, obtenemos los resultados siguientes:

\begin{tabular}{|c|c|c|c|c|c|c|c|c|}
\hline & \multicolumn{2}{|c|}{ poner } & \multicolumn{2}{|c|}{ meter $_{\text {esp }}$} & \multicolumn{2}{|l|}{ pôr } & \multicolumn{2}{|c|}{ meter $_{\mathrm{ptg}}$} \\
\hline & \# & $\%$ & \# & $\%$ & \# & $\%$ & \# & $\%$ \\
\hline pôr & 335 & 94.6 & 16 & 13.7 & & & & \\
\hline meter $_{\mathrm{ptg}}$ & 19 & 5.4 & 101 & 86.3 & & & & \\
\hline total & 354 & 100 & 117 & 100 & & & & \\
\hline poner & & & & & 335 & 95.4 & 19 & 15.8 \\
\hline meter $_{\text {esp }}$ & & & & & 16 & 4.6 & 101 & 84.2 \\
\hline total & & & & & 351 & 100 & 120 & 100 \\
\hline
\end{tabular}

Tabla 2: Equivalencias binomios

Del cuadro 2 se desprende que domina claramente el uso de poner (354 casos) y de pôr (351 casos), mientras que el uso de meter $_{\text {esp/ptg }}$ en ambas lenguas resulta más restringido (117 en esp. vs. 120 en ptg.). Este hecho sugiere que en ambas lenguas el uso de poner/pôr es más variado y amplio que el de meter $_{\text {esp }} /$ meter $_{\text {ptg. }}$. Se observa también que en general el grado de correspondencia entre los cognados morfológicos es bastante alto (11-12) (alrededor de un 95\% en ambas direcciones):

(11a) Ah, pues has puesto el dedo en la llaga - dijo el Sr. Weasley con una risa sarcástica. (HPOF-ESP: 52)

(11b) Ah, bom, puseste o dedo na ferida! - exclamou Mr. Weasley, com um sorriso forçado. (HPOFPTG: 87)

(12a) Ron metió el chivatoscopio en un calcetín especialmente horroroso de tío Vernon, que ahogó el silbido, y luego cerró el baúl. (HPPA-ESP: 38)

(12b) Ron meteu o Avisoscópio num horroroso par de peúgas velhas do tio Vernon que abafaram o som e a seguir fechou o malão. (HPPA-PTG: 67)

Solo en un número limitado de contextos (el 7.4\% o 35/471 de cada lengua) se opta por la traducción mediante otro miembro del binomio (13-14):

(13a) Puedes ponerlos en sobres -le dijo a Ginny, lanzando las fotos firmadas en su regazo uno por uno cuando los terminó-. (HPOF-ESP: 278)

(13b) - Podes metê-las nos envelopes - dizia para Ginny, atirando as fotografias autografadas para o colo dela, à medida que as assinava. (HPOF-PTG: 440)

(14a) Moody cogió la araña trapecista y la volvió a meter en el tarro. (HPCF-ESP: 105)

(14b) Moody pegou na aranha às cambalhotas e voltou a pô-la no pote de vidro. (HPCF-PTG: 177)

Cabe notar que estos casos de no equivalencia son casi todos ejemplos pertenecientes al núcleo semántico locativo (67 de los 70 casos en total). Es decir, los contextos en los que meter $_{\text {esp }}$ o meter $_{\text {ptg }}$ pueden funcionar como traducción equivalente de $p \hat{o} r / p o n e r$ o viceversa se restringen principalmente al ámbito locativo.

Finalmente, los datos cuantitativos muestran que en los contextos semánticos en que el traductor español optó por meter ${ }_{e s p}$, el traductor portugués eligió más frecuentemente el lexema pôr (13.7\% de los casos analizados) que al revés: al verbo pôr en portugués le corresponde menos meter $_{\text {esp }}$ en español (solo en un $4.6 \%$ de los ejemplos con pôr). Paralelamente podemos observar que a meter $_{\text {ptg }}$ le corresponde más frecuentemente poner en 
español (15.8\%) que en el caso contrario: apenas un 5.4\% de los casos de poner coincide con meter $_{p t g}$ en portugués. Esta constatación indica que los verbos meter $_{\text {esp }} /$ meter $_{\text {tg }}$ se caracterizan por un campo operativo mucho más restringido que sus homólogos poner y pôr.

Resumiendo, los cognados morfológicos presentan un grado de correspondencia bastante elevado, y las fluctuaciones entre cuasi-sinónimos no cognados ocurren casi únicamente en contextos locativos. Asimismo, el uso de poner/pôr resulta más variado y frecuente que el de meter $_{\text {esp }} /$ meter $_{\text {ptg. }}$. Ahora conviene comprobar y profundizar en estas afirmaciones en un corpus comparable, y buscar los factores explicativos.

\section{Estudio de caso 2: grado de equivalencia interlingüística en un corpus comparable}

\subsection{Frecuencias relativas de los usos}

Con el fin de determinar la distribución de los núcleos semánticos, hemos compuesto un corpus bien equilibrado y representativo de 769 casos concretos de los cuatro verbos estudiados. Los datos para el español provienen del banco de datos CREA, del que hemos extraído arbitrariamente ejemplos tanto de textos de prensa como de ficción. Los casos del portugués igualmente han sido seleccionados arbitrariamente en artículos de prensa y novelas de ficción. $^{12}$

La tabla 3 ofrece una imagen de la distribución de los cuatro núcleos semánticos para cada uno de los cuatro verbos:

\begin{tabular}{|l|c|c|c|c|c|c|c|c|}
\hline \multirow{2}{*}{} & \multicolumn{3}{|c|}{ Poner } & \multicolumn{2}{c|}{ Meter $_{\text {esp }}$} & \multicolumn{2}{c|}{ Pôr } & \multicolumn{2}{c|}{ Meter $_{\text {ptg }}$} \\
\cline { 2 - 11 } & $\#$ & $\%$ & $\#$ & $\%$ & $\#$ & $\%$ & $\#$ & $\%$ \\
\hline uso locativo & 56 & 28 & 160 & $\mathbf{8 0}$ & 76 & $\mathbf{3 8}$ & 144 & $\mathbf{8 5 . 2}$ \\
\hline uso de transferencia & 29 & 14.5 & 9 & 4.5 & 25 & 12.5 & 7 & 4.1 \\
\hline uso causativo/incoativo & 16 & 8 & 2 & 1 & 35 & 17.5 & - & - \\
\hline uso pred. del sujeto/objeto & 59 & $\mathbf{2 9 . 5}$ & 9 & 4.5 & 46 & 23 & - & - \\
\hline caso ambiguo & 12 & 6 & 6 & 3 & 6 & 3 & 2 & 1.2 \\
\hline otro & 28 & 14 & 14 & 7 & 12 & 6 & 16 & 9.5 \\
\hline & 200 & 100 & 200 & 100 & 200 & 100 & 169 & 100 \\
\hline
\end{tabular}

Salta a la vista el gran desequilibrio de las proporciones entre los verbos meter $_{\text {esp }} /$ ptg, que expresan más frecuentemente el núcleo semántico locativo, y poner/pôr, que se extienden relativamente más frecuentemente al uso predicativo y/o incoativo/causativo.

Aparte de los cuatro usos y su frecuencia para cada verbo, la tabla 3 nos enseña también la existencia de varios casos ambiguos. Es decir, la frontera entre los usos no siempre resulta tan nítida, y observamos múltiples casos que se sitúan a medio camino entre dos núcleos semánticos, provocando así una ambigüedad. Así, en el ejemplo (15), el uso locativo y el uso de transferencia están entrelazados. Efectivamente, sintácticamente se observa la coincidencia de un complemento de lugar (el locativo), y el dativo (como receptor del codazo).

\footnotetext{
${ }^{12}$ Para más informaciones sobre la constitución del corpus, véase Bibliografía (cf. infra). El banco de datos portugués solo contiene 169 ocurrencias de meter $_{p t g}$, lo cual explica la proporción más baja de casos analizados.
} 
(15) $[\mathrm{Su} \text { mujer pintarrajeada como un muñecote }]_{\mathrm{P} 1}[\ldots][\text { le }]_{\mathrm{P} 3}$ metió $[\text { un codazo }]_{\mathrm{P} 2}$ [en el estómago $]_{\mathrm{loc}} \mathrm{y}$ el otro, cogido en falta, se quedó callado de golpe, avergonzado, morro-morro. (CREA: SánchezOstiz Miguel, 1995)

También se observan casos a caballo entre el uso locativo y el uso predicativo. El ejemplo (16) puede interpretarse como uso locativo por la presencia de la base nos copos, pero también se acerca del uso predicativo: la persona se mete o entra en el estado de borrachera:

(16) Tem sempre ideias dessas, quando [se $]_{P 2} / P 1$ refl mete $[\text { nos copos }]_{\mathrm{loc}}$ ? (CRPC: Botelho Fernanda, 1987)

En lo que sigue estudiaremos más en detalle las diferencias entre ambas lenguas iberorromances y los lexemas, respectivamente para el núcleo locativo (4.2), el núcleo de transferencia (4.3), el núcleo incoativo/causativo (4.4) y el predicativo (4.5). Con el fin de obtener un grado de representatividad más alto, el corpus básico ha sido ampliado a 2146 casos.

\subsection{El núcleo locativo}

De la tabla 3 se desprende que los verbos meter $_{\text {esp } p \text { tg }}$ funcionan cada uno como verbos locativos básicos en la mayoría aplastante de los casos (el 80\% y el 85.2\%). En cambio, la proporción de eventos locativos para poner y pôr ni siquiera alcanza el 50\%, por lo que el núcleo locativo de estos verbos parece menos dominante.

El uso locativo prototípico se define por la presencia de un $\mathrm{P}_{1}$ humano que transfiere un $\mathrm{P}_{2}$ inanimado concreto a una base inanimada concreta (cf. sección 2). Sin embargo, el corpus comparable demuestra que a menudo los usos locativos de poner/pôr/meter esp/ptg se alejan del modelo locativo prototípico al presentar una serie de extensiones semánticas. Concretamente se trata de localizaciones metafóricas realizadas por participantes menos prototípicos, como un $\mathrm{P}_{1}$ inanimado (17), completado por un $\mathrm{P}_{2}$ humano y un locativo abstracto (18), un $\mathrm{P}_{2}$ inanimado abstracto (19) o una base humana (20):

(17) Pasó [un Volvo color gris plata] $]_{\mathrm{P} 1}$, metió [una de sus ruedas] $]_{\mathrm{P} 2}$ [en un charquito putrefacto] $]_{\mathrm{loc}} \mathrm{y}$ salpicó a Juan Antonio manchándole los pantalones. (CREA: Marsillach Adolfo, 1995)

(18) $[\mathrm{El} \text { azar }]_{\mathrm{P} 1}$ puso [en mi camino $]_{\mathrm{loc}}$ [al juez García Mouriños $]_{\mathrm{P} 2}$. (CREA: Giménez Bartlett Alicia, 2002)

(19) Porei [um bocadinho de ironia $]_{\mathrm{P} 2}$ [na minha voz $]_{\mathrm{loc}}$, a dose necessária e suficiente. Ela compreenderá. (CRPC: Botelho Fernanda, 1960)

(20) Londres, Paris, Boston: em qualquer destas cidades havia [um médico $]_{\mathrm{loc}},[\ldots]$ em que se punham [todas as esperanças $]_{\mathrm{P} 2}$. (CRPC: Baptista António Alçada, 1985)

En el corpus comparable ampliado, poner ocurre con más frecuencia en contextos locativos prototípicos, en el $56.1 \%$ respectivamente, si bien la proporción de extensiones semánticas (cf. ejemplo 18) también resulta considerable, a saber el 43.9\%. Sin embargo, la prototipicidad 'conceptual' o 'semántica' no siempre coincide con una frecuencia más alta en el corpus. Así, meter $e_{e s p}$ expresa mayoritariamente localizaciones de índole menos prototípica (incluso en el 73.1\%), y solo se utiliza para usos locativos prototípicos en el $26.9 \%$. La presencia dominante de extensiones semánticas con meter $_{\text {esp }}$ se explica por su fuerte inclinación por un $\mathrm{P}_{2}$ animado (en el $64.1 \%$ de los usos locativos), que frecuentemente coincide con el uso reflexivo del verbo: 


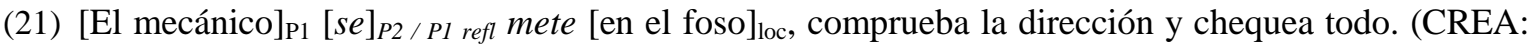
Mañas José Ángel, 1994)

Aparentemente, la naturaleza semántica de los participantes parece ser un factor importante que influye en la elección de uno u otro verbo en español. ${ }^{13}$

En portugués, pôr expresa mayoritariamente localizaciones prototípicas (62.1\%), al igual que poner en español. Los contextos prototípicos de meter $_{\text {ptg }}$ se elevan al $48 \%$, por lo que su perfil semántico no es tan diferente del de pôr, contrariamente a lo que observamos en español. Meter $_{\text {ptg }}$ también presenta un número considerable de localizaciones menos prototípicas con $\mathrm{P}_{1}$ reflexivo animado, a saber en el 35.5\%, más que pôr (8.5\%) o poner $(11.2 \%)$.

(22) A Teresa desligou o telefone. Seguiu para a casa de banho, meteu- $[s e]_{P 2} / P 1$ refl $[\text { no chuveiro }]_{\text {loc. }}$. (CRPC: Baptista António Alçada, 1985)

Así pues, el análisis semántico del núcleo locativo nos permite concluir que los cognados morfológicos interlingüísticos se corresponden bastante bien entre sí.

Además, estos cognados se asemejan también por lo que concierna la direccionalidad del evento locativo. Efectivamente, según la teoría de Cifuentes Honrubia (1996: 103-139), poner se define como verbo posicional y meter $_{e s p}$ como verbo de direccionalidad interior. Para averiguar la validez de esta hipótesis en ambas lenguas, clasificamos las preposiciones con las que se combinan los cuatro lexemas según su valor semántico y más particularmente la dirección locativa que expresan.

Primero, prevemos una subclase [- dirección] para usos locativos que no expresan explícitamente una dirección, con una base que corresponde sintácticamente a un adverbio (Pongo el libro aquí) o un pronombre interrogativo (¿Dónde te has metido?). Aparte de estos casos de [- dirección], se distinguen las categorías siguientes: (i) localizaciones de dirección interior, cuya preposición siempre puede sustituirse por dentro de, (ii) localizaciones en el eje horizontal, (iii) localizaciones en el eje vertical, y (iv) localizaciones en otra dirección que las antedichas. ${ }^{14}$ En el eje vertical es posible poner el $\mathrm{P}_{2}$ encima o debajo de una base. En el eje horizontal, se puede poner el $\mathrm{P}_{2}$ delante o detrás de una base, yuxtaponerlo al lado de esta base, o interponerlo entre dos bases diferentes. Además, cabe añadir que las direcciones distinguidas se pueden interpretar en sentido tanto literal como figurado. Así por ejemplo, las ubicaciones de dirección interior comportan tanto eventos locativos concretos (23a) como metafóricos (23b):

(23a) i[Te $]_{\mathrm{P} 2}$ meteré [en el manicomio $]_{\text {loc }}$ (CREA: Carrión Ignacio, 1995)

(23b) $[\mathrm{Se}]_{\mathrm{P} 2 / \mathrm{P} 1 \text { refl }}$ metía [en el pellejo del jugador que perdía $]_{\mathrm{loc}} \mathrm{y}$ se lamentaba con más contundencia. (CREA: Pozo Raúl del, 1995)

El cuadro 4 muestra la distribución porcentual de las direcciones que expresan poner/pôr/meter esp/ptg como verbos locativos:

\footnotetext{
${ }^{13}$ Esta hipótesis merece un análisis más detenido en investigaciones futuras.

${ }^{14}$ Esta categoría comporta ejemplos de tipo: Algunas veces se ponía siete aros juntos en una muñeca. (CREA: Pérez-Reverte Arturo, 2002). En este caso, la preposición expresa otra dirección que la interior, vertical o horizonal.
} 


\begin{tabular}{|c|c|c|c|c|c|c|c|c|}
\hline & \multicolumn{2}{|c|}{ Poner } & \multicolumn{2}{|c|}{ Meter $_{\text {esp }}$} & \multicolumn{2}{|c|}{ Pôr } & \multicolumn{2}{|c|}{ Meter $_{\mathrm{ptg}}$} \\
\hline & $\#$ & $\%$ & \# & $\%$ & $\#$ & $\%$ & $\#$ & $\%$ \\
\hline [- dirección] & 10 & 3.6 & 30 & 6.9 & 36 & 8.7 & 16 & 3.5 \\
\hline [+ dirección] interior (dentro) & 91 & 32.6 & 348 & 80.6 & 110 & 26.6 & 347 & 76.8 \\
\hline [+ dirección] horizontal delante & 15 & 5.4 & - & - & 10 & 2.4 & 3 & 0.7 \\
\hline [+ dirección] horizontal neutro (interposición) & 4 & 1.4 & 6 & 1.4 & 6 & 1.5 & 6 & 1.3 \\
\hline [+ dirección] horizontal detrás & 2 & 0.7 & 2 & 0.7 & 1 & 0.2 & 1 & 0.2 \\
\hline [+ dirección] horizontal lateral (yuxtaposición) & 17 & 6.1 & 2 & 0.7 & 26 & 6.3 & 4 & 0.9 \\
\hline [+ dirección] vertical encima & 122 & 43.7 & 7 & 1.6 & 193 & 46.7 & 12 & 2.7 \\
\hline [+ dirección] vertical debajo & 6 & 2.2 & 13 & 3 & 4 & 1 & 16 & 3.5 \\
\hline [+ dirección] otra dirección & 12 & 4.3 & 24 & 5.6 & 27 & 6.5 & 49 & 10.8 \\
\hline Total & 279 & 100 & 432 & 100 & 413 & 100 & 452 & 100 \\
\hline
\end{tabular}

Tabla 4. El núcleo locativo de poner/pôr/meter esp $_{\text {/meter }}$ ptg y la dirección de la localización

Concretamente, en ambas lenguas meter $_{\text {esplptg }}$ se inclinan decididamente por la dirección interior, respectivamente en el $80.6 \%$ y el $76.8 \%$ de los casos locativos (ejemplos 24,25 ). Por su parte, poner y pôr se muestran más propensos a la dirección vertical (encima) (43.7\% y 46.7\%) (26, 27). Por ende, la caracterización semántica de Cifuentes Honrubia (1996) para los verbos españoles se aplica también a sus cognados en portugués:

(24) $[\text { Carlos }]_{\mathrm{P} 1}$ se metió [las manos $]_{\mathrm{P} 2}$ [en los bolsillos del pantalón $]_{\mathrm{loc}} \mathrm{y}$ descubrió -le daba igual- que en uno de ellos tenía un agujero. (CREA: Marsillach Adolfo, 1995)

(25) Tão apalermado estava que trocou as pontas ao cigarro, meteu [o lado aceso $]_{\mathrm{P} 2}$ [na boca $]_{\mathrm{loc}} \mathrm{e}$ chupou, só quem alguma vez passou por isso sabe como dói. (CRPC: Zambujal Mário, 1980)

(26) Pone [el dedo índice de su mano derecha $]_{\mathrm{P} 2}$ [sobre la yugular de su víctima] $]_{\mathrm{loc}} \mathrm{y}$ comprueba el ritmo de su corazón. (CREA: Hernández Ramón, 1995)

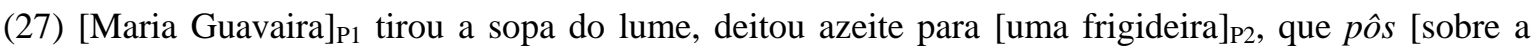
trempe $]_{\text {loc }}$ (CRPC: Saramago José, 1985)

Llama la atención que el núcleo locativo de poner y pôr parece más amplio que el de

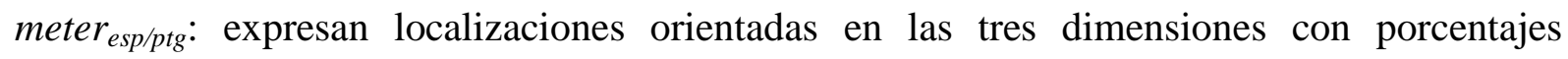
bastante repartidos: tanto la interioridad $(32.6 \%$ y $26.6 \%$ para resp. poner y pôr), como la dirección horizontal (13.6\% y $10.4 \%$ ) y vertical $(45.9 \%$ y $47.7 \%)$. Al revés, meter $e_{e s p} \mathrm{y}$ meter $_{p t g}$ tienen un uso más especializado: sus contextos locativos se ciñen mayoritariamente a una sola dirección, la interior, mientras que las localizaciones en el eje horizontal y vertical se reducen a porcentajes mínimos (meter esp $_{2}$. $2.8 \%$ y $4.6 \%$; meter $_{p t g}: 3.1 \%$ y $6.2 \%$ ).

Resumiendo, en su uso locativo los cognados morfológicos interlingüísticos presentan en gran medida correspondencias mutuas. No obstante, este núcleo resulta menos dominante y saliente para poner y pôr. Además, las localizaciones que expresan son más frecuentemente prototípicas y se orientan en varias direcciones entre las cuales predomina la vertical. En

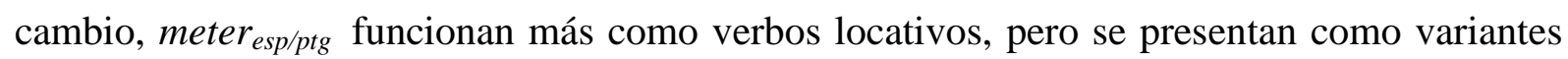
más restringidas en cuanto a la direccionalidad que poner y pôr. Resulta, por fin, que sobre todo meter $_{\text {esp }}$ parece semánticamente muy especializado, dada su preferencia marcada por contextos no prototípicos, a menudo pronominales. 


\subsection{El núcleo de transferencia}

Por lo que atañe al núcleo de transferencia (cf. tabla 3), los cognados morfológicos presentan otra vez frecuencias relativas muy similares. En español, poner se utiliza más frecuentemente para transferencias que meter $_{\text {esp }}(14.5 \%$ vs. $4.5 \%)$, tal y como pôr en portugués se presta más a este uso que meter $_{\text {ptg }}(12.5 \%$ vs. $4.1 \%)$.

También este uso del verbo se aparta con frecuencia de la configuración prototípica (cf. los ejemplos 2a-c): el $\mathrm{P}_{1}$ no siempre resulta humano ni dotado de autocontrol (28), el participante transferido $\mathrm{P}_{2}$ no siempre es una entidad concreta $(28,29,30)$, y el receptor $\mathrm{P}_{3}$ también puede ser un concepto abstracto $(29,30)$ o un ente inanimado concreto (31) en vez de un ser humano:

(28) ¿Qué edad tiene el mozalbete? -inquirió Barceló, mirándome de reojo.- Casi once años -declaré. Barceló me sonrió, socarrón. - O sea, diez. No te pongas años de más, sabandijilla, que ya [te $]_{\mathrm{P} 3}$ [los $]_{\mathrm{P} 2}$ pondrá [la vida $]_{\mathrm{P} 1}$. (CREA: Ruiz Zafón Carlos, 2001)

(29) Arruinó la fiesta y [le $]_{\mathrm{P} 3}$ puso [tal tensión $]_{\mathrm{P} 2}[\mathrm{al} \text { ambiente }]_{\mathrm{P} 3}$ que ya todos se sintieron molestos y empezaron a irse. (CREA: Salvador Caja Gregorio, 2002)

(30) Pero ésta es también la historia de Jonet, [el niño flautista $]_{\mathrm{P} 1}$ que puso [furia $]_{\mathrm{P} 2}$ [a la música $]_{\mathrm{P} 3}$ mientras el ciego la ungía de dulzura. (CREA: Moix Terenci, 2002)

(31) [...] Podía haber pensado en los regalos. Yo los compré, yo los envolví, [yo $]_{\mathrm{P} 1}[\text { les }]_{\mathrm{P} 3}$ puse [los lacitos] $]_{\mathrm{P} 2}$, yo les pegué las etiquetas. (CREA: Rico Godoy Carmen, 1990).

En el corpus español, poner aparece en contextos de transferencia más diversos que meter $_{\text {esp }}$. Se utiliza para transferencias prototípicas (49.2\%), pero también para extensiones metafóricas (50.8\%), como en los ejemplos (28) - (31) arriba. Con meter ${ }_{e s p}$, las posibilidades de combinación son más limitadas, y su uso se restringe mayoritariamente $(81.3 \%)$ a transferencias virtuales de un $\mathrm{P}_{2}$ abstracto (32).

(32) Les vi indignados. Pero ¿qué quieres? ¿Que [les $]_{\mathrm{P} 3}$ meta $[\text { media hora }]_{\mathrm{P} 2}$ para poder relajarte?, fue la agresiva contestación de uno. Eres un aguafiestas. (CREA: García Sánchez Javier, 1994)

El verbo meter $_{p t g}$ también resulta semánticamente más restringido que pôr. Tal como meter ${ }_{e s p}$ en español, meter $_{p t g}$ prefiere mayoritariamente una entidad abstracta como objeto transferido $(87.5 \%) .^{15}$

(33) Apenas dois retratos desmedidos nas paredes nuas: o do bisavô Lourenço, com [uns bigodes] $]_{\mathrm{P} 1}$ que outrora $[\mathrm{lhe}]_{\mathrm{P} 3}$ metiam [medo] $]_{\mathrm{P} 2}$, sobretudo se tinha arreliado a Estefânia, e aqueles olhos, negros, fundos, perdição de almas e de corpos. (CRPC: Dacosta Luísa, 1969)

Por su parte, pôr se parece también a poner, y admite contextos de transferencia más variados: tanto prototípicos (34a) (52.4\%) como metafóricos (34b) (47.6\%):

(34a) [A mãe do senhor professor $]_{\mathrm{P} 1}$ pôs-[lhe $]_{\mathrm{P} 3}$ ao almoço [um ovo estrelado $]_{\mathrm{P} 2}[\ldots . .$. . Não se levantem da mesa com fome! (CRPC: Ribeiro Aquilino, 1989)

(34b) -A propósito, diz-me cá: puseram-[te $]_{\mathrm{P} 3}$ ao menos [um nome $]_{\mathrm{P} 2}$, tens um nome mesmo teu? Como te chamas? (CRPC: Tojal Altino do, 1984)

Así pues, para el uso de transferencia los cognados morfológicos presentan bastante correspondencia entre sí, más que sus cuasi-sinónimos dentro de ambas lenguas. Además, los verbos poner y pôr no solo se utilizan más frecuentemente como verbos de transferencia que

\footnotetext{
${ }^{15}$ Este hecho explica probablemente por qué no encontramos ejemplos de una transferencia prototípica con meter $_{\text {ptg }}$ en los diccionarios analizados (cf. supra sección 2).
} 
meter $_{\text {esp/ptg }}$, sino que también abarcan una gama de contextos más amplios dentro de este núcleo.

\subsection{El núcleo incoativo y causativo}

La tabla 3 nos enseña que, de los cuatro verbos, sobre todo pôr y poner pueden funcionar como verbos causativos (poner a alguien a trabajar) e incoativos (ponerse a trabajar); además y pôr (27 casos o un 17.5\%) lo hace relativamente más frecuentemente que poner (7 casos o un 8\%). Esta discrepancia explica al mismo tiempo por qué en las traducciones españolas (cf. sección 3.2, ejemplos 8-9) se tiende a la no traducción del aspecto incoativo, contrariamente a lo que ocurre en las correspondientes traducciones portuguesas, donde se recurre a pôr-se $a+i n f$. Talvez poner aún no ha pasado en igual medida que pôr por el proceso de auxiliarización (Lehmann 2008: 2) en el que el verbo pierde parte de su significado locativo original, al funcionar como semi-auxiliar aspectual. Además, para meter $_{\text {esp }}$ y meter $_{\text {tg }}$ el uso causativo/incoativo resulta muy limitado y casi inexistente (respectivamente $1 \%$ y $0 \%$ ).

En el uso causativo prototípico, un causante animado instiga a otro participante $\mathrm{P}_{2}$ animado a efectuar una acción. En el uso incoativo reflexivo, el $\mathrm{P}_{1}$ también es prototípicamente animado. Sin embargo, en contextos menos prototípicos ni el $\mathrm{P}_{1}$ (35) ni el $\mathrm{P}_{2}$ (36) refieren a seres humanos:

(35) Insistia Branca vendo que [a tarde $]_{P 1}[s e]_{P 1}$ refl punha a cair sem que José se mexesse dessa mesma posição. (CRPC: Jorge Lídia, 1980)

(36) Pus [a água $]_{P 2}$ a correr, quase que me queimei quando entrei na banheira, respirei fundo e acordei com frio. (CRPC: Correia Hélia, 1988)

En el corpus pôr aparece en contextos prototípicos en el 76\%, y poner en el 92\%. Así pues, el núcleo causativo/incoativo de estos verbos parece semánticamente bastante más restringido, centrado mayoritariamente en el prototipo con participantes animados, poner aún más que pôr.

En cuanto al tipo de infinitivo seleccionado, poner y pôr también se asemejan: tienen ambos una preferencia marcada por infinitivos intransitivos en el uso causativo (el $83.3 \%$ y el $77.4 \%$ respectivamente), como correr en el ejemplo (36) arriba. En cambio, el uso incoativo se caracteriza por infinitivos tanto transitivos (37a) (35.2\% para poner y $43.5 \%$ para pôr) como intransitivos (37b) (36.4\% para poner y $40.6 \%$ para pôr) con porcentajes más equilibrados:

(37a) $\mathrm{Y}$ entonces [uno de sus almuédanos $]_{\mathrm{P} 1}$ se subió encima de ellas y [se $]_{\mathrm{P} 1 \text { refl }}$ puso a alabar a su profeta como desde un púlpito. (CREA: Torbado Jesús, 1993)

(37b) Una vieja pasa con un caniche negro feísimo y nos mira. Yo le saco la lengua y [el caniche $]_{\mathrm{P} 1}$ $[\text { [se }]_{\mathrm{P} 1 \text { refl }}$ pone a ladrar. (CREA: Mañas José Ángel, 1994)

Constatamos también que, tanto en el uso causativo como en el uso incoativo, los infinitivos intransitivos suelen ser inergativos (en el $90.5 \%$ para poner, y el $90.4 \%$ para $p o ̂ r$ ). Estos datos confirman lo esperado: en el $85 \%$ y el $73 \%$, el infinitivo de poner y pôr expresa un evento dinámico que implica una acción o un movimiento. Es decir, nunca se trata de un estado, o como dice Lamiroy (1991: 133, 100), el uso causativo/incoativo no parece ser compatible con 
infinitivos estáticos (*Jorge se puso a poseer muchas tierras, *Jorge pone la botella a estar fresca). ${ }^{16}$

Por su parte, meter $_{\text {esp/ptg }}$ casi no se prestan al uso causativo ni incoativo. Los pocos ejemplos disponibles en el corpus constituyen todos casos incoativos en contextos prototípicos. El infinitivo de meter $_{e s p}$ puede ser intransitivo inergativo (30\%) (38a) o transitivo $(45 \%)(38 b)$ :

(38a) Siempre había gente cerca, [las vecinas de la puerta de al lado $]_{\mathrm{P} 1}$ que te escuchaban aunque no hablaras alto y que con cualquier pretexto $[s e]_{\mathrm{Pl} \text { refl }}$ metían a fisgar en tu casa, algunas con muy mala idea. (CREA: Muñoz Molina Antonio, 2001)

(38b) [Isabel y Fabián $]_{\mathrm{P} 1}$ dejaron el convento y $[\text { se }]_{\mathrm{P} 1 \text { refl }}$ metieron a tomar unas enchiladas en una casa de comidas y a hacer planes. (CREA: Pombo Álvaro, 2004)

En resumen, también en el uso causativo/incoativo los cognados muestran una fuerte correspondencia entre sí. Sin embargo, los usos causativos/incoativos de poner se alejan en menor medida del modelo prototípico que los de pôr, y pôr parece funcionar con más frecuencia como auxiliar causativo/incoativo que su homólogo español.

\subsection{El núcleo predicativo de cambio}

Al igual que en el uso incoativo/causativo, está claro que solo poner y pôr tienen un uso predicativo 'verdadero' o significativo: según las frecuencias relativas presentadas en la tabla 3 , poner y pôr funcionan como verbos predicativos en el $29.5 \%$ y $23 \%$ respectivamente. Para meter $_{\text {esp }}$ un mero $4.5 \%$ aparece como caso predicativo, y para meter $_{p t g}$ el corpus no procura ejemplos.

En el contexto del núcleo predicativo que prototípicamente denota un cambio de estado en un ser humano (cf. los ejemplos 4a-d), se distinguen también varias extensiones semánticas, en particular cuando el $\mathrm{P}_{1}$ (39) o el $\mathrm{P}_{2}$ (40) carecen del rasgo humano. ${ }^{17}$

(39) [...] al cruzar una de aquellas avenidas tan anchas en las que [el semáforo $]_{\mathrm{P} 1}$ siempre $[\text { se }]_{\mathrm{P} 1 \text { refl }}$ ponía [en rojo $]_{\text {pred. suj. }}$ antes de llegar al otro lado. (CREA: Muñoz Molina Antonio, 2001)

(40) $[\text { Mi padre }]_{P 1}$ puso [los ojos $]_{P 2}$ [en blanco $]_{\text {pred.obj. }}$ - Con usted es imposible discutir, Fermín. - Es que si tengo razón, tengo razón. (CREA: Ruiz Zafón Carlos, 2001)

Para poner, el corpus contiene usos predicativos tanto prototípicos $(51.7 \%)$ como extensiones semánticas (48.3\%). Para pôr estos porcentajes alcanzan el $58.6 \%$ y el $41.4 \%$ respectivamente. Por consiguiente, estos cognados morfológicos no presentan grandes aberraciones entre sí.

Estudios previos recurren a la índole del atributo o del complemento predicativo para explicar el uso predicativo de cambio de verbos particulares. Así, Van Gorp (2012: 396-397,

\footnotetext{
${ }^{16}$ Aunque el grado de dinamicidad de la acción sí puede variar y no siempre resulta tan elevado: $[M e]_{\mathrm{P} 1 \text { refl }}$ puse a esperar un taxi benévolo, en el cual me dejaran fumar y sobre todo no me regañaran. (CREA: Rico Godoy Carmen, 1990).

${ }^{17}$ Nótese que estas frases se distinguen lo más claramente del uso locativo: no se trata de un cambio de lugar, sino de un cambio de estado: el semáforo se pone en estado rojo, el padre pone los ojos en estado blanco. Además, se nota que el uso predicativo no forzosamente expresa siempre un cambio de estado de ánimo (ponerse nervioso), sino que también puede tratarse de un cambio de estado físico por ejemplo.
} 
399) distingue entre tres categorías, según el tipo de cambio de estado expresado: un cambio del estado de ánimo (ponerse nervioso), de la salud (ponerse enfermo) y cambios relacionados con adjetivos de color (ponerse rojo). El atributo de la estructura pseudo-copulativa con ponerse suele denotar un estado transitorio y no duradero, lo cual, según el análisis de la autora, se motiva por el carácter reversible o temporal del significado léxico básico de poner como verbo de localización. ${ }^{18}$

En el corpus se distinguen cambios que expresan un estado de ánimo, un estado físico o un cambio de profesión (meterse monja). Los estados físicos comportan los estados de salud y los adjetivos de color, pero también otros estados físicamente observables. Así, en el ejemplo (41), las cartas de tarot también sufren un cambio de estado físico:

(41) $[\text { Las cartas de tarot }]_{\mathrm{P} 2}$ que [ella misma $]_{\mathrm{P} 1}$ pone [boca arriba $]_{\text {pred.obj. }}$ (CREA: Pérez-Reverte Arturo, 2002)

En fin, bajo la etiqueta 'otro' agrupamos los cambios de estado que no caben en las categorías antedichas: poner a alguien en libertad (o sea, en estado libre), poner a alguien de ejemplo, por testigo etc. La clasificación de los ejemplos según estos criterios da el resultado siguiente:

\begin{tabular}{|l|c|c|c|c|c|c|c|c|}
\hline & \multicolumn{2}{|c|}{ Poner } & \multicolumn{2}{c|}{ Meter $_{\text {esp }}$} & \multicolumn{2}{c|}{ Pôr } & \multicolumn{2}{|c|}{ Meter $_{\text {ptg }}$} \\
\cline { 2 - 10 } & $\#$ & $\mathbf{\%}$ & $\#$ & $\mathbf{\%}$ & $\#$ & $\mathbf{\%}$ & $\#$ & \% \\
\hline Estado de ánimo & 66 & $\mathbf{4 4 . 9}$ & 1 & 14.3 & 26 & $\mathbf{4 4 . 8}$ & - & - \\
\hline Estado físico & 57 & 38.8 & - & - & 21 & 36.2 & - & - \\
\hline Profesión & 1 & 0.7 & 1 & 14.3 & - & - & 1 & 25 \\
\hline Otro & 23 & 15.7 & 5 & $\mathbf{7 1 . 4}$ & 11 & 19 & 3 & $\mathbf{7 5}$ \\
\hline Total usos predicativos & 147 & 100 & 7 & 100 & 58 & 100 & 4 & 100 \\
\hline
\end{tabular}

Tabla 5. El núcleo predicativo de cambio de poner/pôr/meter ${ }_{\text {esp }} /$ meter $_{\text {ptg }}$ y el tipo de atributo

Resulta que poner y pôr funcionan mucho más frecuentemente como verbos predicativos que meter $_{\text {esp }} /$ meter $_{\text {ptg }}$, y poner aún más que pôr. Poner y pôr expresan ambos a menudo cambios del estado de ánimo, y los atributos más frecuentes son: nervioso, pesado, de mal(a) humor/leche, triste, de buen humor y serio en español, y quieto, sério, trémulo o variantes de colérico (irado, rubro de cólera, em cólera) en portugués.

Además, el uso predicativo de poner y pôr cubre generalmente un cambio de estado transitorio: en el $89.9 \%$ de todos los casos predicativos con poner, y en el $86.2 \%$ de los casos con pôr, el estado resultante no es no duradero, y el cambio tampoco es definitivo ni intrínseco:

(42) Tienes que descansar, que sabes que las lágrimas y $[\text { las ojeras }]_{\mathrm{P} 1}[\text { te }]_{\mathrm{P} 2}$ ponen $[\text { feísima }]_{\text {pred.obj. }}$ (CREA: Beccaria Lola, 2001)

(43) Porém, [o queixo dela $]_{\mathrm{P} 1}$, ligeiramente barbado, põe-[se $]_{\mathrm{P} 1 \text { refl }}[\text { trémulo }]_{\text {pred.suj., }}$ como num assomo súbito da doença de Parkinson. (CRPC: Melo João de, 1988)

La escasez de datos no da pie para sacar conclusiones generales en cuanto a la naturaleza semántica preferida de los argumentos de meter $_{\text {esp/ptg }}$, aunque sí se observa cierta tendencia. A saber, en los pocos ejemplos disponibles, meter ${ }_{\text {esp }}$ y meter $_{\text {ptg }}$ expresan a menudo un estado permanente y durativo más bien que temporal: un estado de locura (44), un estado físico

\footnotetext{
${ }^{18}$ Por ejemplo, unos libros puestos en una mesa se pueden desplazar a otro lugar en cualquier momento, y del mismo modo un estado $\mathrm{X}$ siempre puede cambiar a otro estado $\mathrm{Y}$.
} 
irreversible (45), o profesiones $(46,47)$ que no reciben una interpretación temporal u ocasional (contrariamente a lo que ocurre con poner $(48)^{19}$ ). Así, es de suponer que meter esp/ptg se relacionan menos sistemáticamente con estados transitorios que poner y pôr:

(44) En los silencios y en los gestos creía detectar [pequeños brotes de la locura $]_{\text {pred.suj. }}$ en la que $[s e]_{P 1}$ refl había metido. (CREA: García Sánchez Javier, 1991)

(45) Estaba abriendo una botella de vino. Siempre se rompen los corchos; lo sé desde el principio que se me van a romper. -Trae -dijo Amelia-, no seas calamidad. Si es que [lo $]_{\mathrm{P} 2}$ metes [torcido $]_{\text {pred.obj. }}$ Déjame a mí. (CREA: Martín Gaite Carmen, 1992)

(46) Cuando $[s e]_{\mathrm{P} 1 \text { refl }}$ metió [monja $]_{\text {pred.suj. }}$ [...], la gracia blanca de la toca que le enmarcaba el rostro acrecentaba aún más el color sonrosado de la piel y el aspecto de manzana de sus mejillas. (CREA: Casares Carlos, 1996)

(47) Então, [o padre ali dos Amorins $]_{\mathrm{P} 1}$ meteu-[me $]_{\mathrm{P} 2}$ [de caseira $]_{\text {pred.obj. }}$ na Viçosa. (CRPC: Correia Hélia, 1991)

(48) Me gustaba [...] que me gastara bromas, y me tomara el pelo, y [se $]_{\mathrm{P} 1 \text { refl }}$ pusiera [de portero $]_{\text {pred.suj., }}$ y me invitara a una coca-cola después. (CREA: Grandes Almudena, 2002)

Esta situación se podría explicar por la persistencia léxica (Hopper 1991: 28) de la semántica básica de meter $_{\text {esp/ptg }}$ como verbo locativo, y más particularmente la dirección interior a la que se asocia frecuentemente. El acto de meter una entidad dentro de un contenedor puede considerarse como más permanente (cf. usos como meter a X en la cárcel, meter el comunismo en el país,...) que el simple posicionamiento expresado por poner/pôr.

En suma, poner se utiliza más frecuentemente como verbo predicativo de cambio que los otros tres, aunque en el caso de pôr también es frecuente. El porcentaje menos elevado de pôr respecto a poner se explica posiblemente por el uso frecuente del verbo ficar ${ }_{\text {ptg }}$ en contextos pseudo-copulativos. Por su parte, los verbos meter $_{\text {esp/ptg }}$ cubren raramente este núcleo semántico predicativo, y si lo hacen, se observa una relación semántica bastante fuerte con su significado locativo.

\section{Conclusiones}

Nuestro estudio sobre el grado de equivalencia entre los binomios poner/pôr y meter $_{\text {esp }} /$ meter $_{\text {ptg }}$ nos permite sacar una serie de conclusiones interesantes a varios niveles de análisis lingüístico.

Primero, por lo que concierne el aspecto metodológico, resulta claro que los corpus paralelos y comparables constituyen instrumentos valiosos y complementarios en el análisis de la polisemia de cognados interlingüísticos. El estudio lexicográfico sugirió que los cuatro verbos cubren todos más o menos los mismos núcleos semánticos, sin ofrecer informaciones sobre su distribución ni su frecuencia de uso. El análisis del corpus paralelo ha permitido refinar esta imagen y ha revelado una primera diferencia de uso importante: poner/pôr se utilizan mucho más frecuentemente que meter $_{\text {esp } p t g}$, lo cual sugiere un campo de uso más amplio. Además, los cognados morfológicos muestran un grado de correspondencia semántica bastante fuerte. En una segunda fase, el análisis del corpus comparable ha proporcionado

\footnotetext{
${ }^{19}$ La RAE (2009: 2853) afirma que ponerse seguido de la preposición de y una profesión implica un cambio accidental (Se puso de portero), es decir, no tiene el mismo valor semántico que la construcción con hacerse, que realmente focaliza el ingreso en una actividad profesional (no accidental) (Se hizo portero).
} 
informaciones más precisas sobre la polisemia, las extensiones semánticas de los cuatro verbos, y los factores de falta de correspondencia exacta entre los cognados interlingüísticos.

Luego, cuantitativamente, pôr y sobre todo poner no parecen ser por excelencia verbos locativos. El perfil semántico de meter $_{\text {esp/ptg }}$ es muy diferente: el núcleo locativo constituye de lejos el uso más frecuente y se extiende regularmente a significados locativos metafóricos. Al revés, el uso de verbo de transferencia es más frecuente en el campo de poner y de pôr que el de meter $_{\text {esp } p t g}$, y la misma tendencia se observa para el uso causativo e incoativo y el uso predicativo de cambio de estado. En el uso predicativo, el verbo funciona como pseudocópula, convirtiéndose así en un elemento más gramatical. En el uso incoativo y causativo, el verbo pierde parte de su significado locativo original pleno y se convierte en un semi-auxiliar aspectual.

Tercero, estas observaciones nos permiten formular unas hipótesis acerca del grado de gramaticalización de los cuasi-sinónimos. Desde el punto de vista intralingüístico, queda


en muchos contextos pierden su significado locativo y se extienden a usos más gramaticales, que apenas continúan el rasgo semántico de ‘cambio' (cf. sección 2). Por lo visto, meter esp $_{\text {y }}$ meter $_{\text {ptg }}$ todavía no han pasado por el mismo proceso de desemantización, dada su aparición

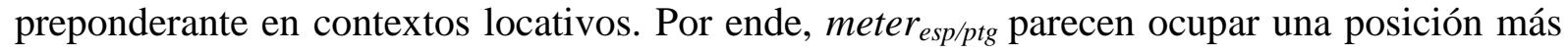
baja en la jerarquía de gramaticalización frente a poner y pôr.

Sin embargo, desde una perspectiva interlingüística los cognados morfológicos tampoco presentan un uso completamente idéntico. En el corpus comparable meter tg $_{g}$ no ocurre ni en el uso causativo, ni incoativo, ni predicativo (cf. supra tabla 3), y parece restringirse fundamentalmente al campo del uso locativo, tanto literal como metafórico. Al revés, meter $_{\text {esp }}$ parece extenderse sobre usos más variados aparte del locativo puro, lo cual puede indicar que se caracteriza por un grado de gramaticalización más alto que su equivalente portugués. Asimismo, poner parece poseer el grado de gramaticalización más elevado, aún más que pôr en portugués. De los cuatro verbos, presenta el menor porcentaje de usos locativos, y su campo operativo se extiende sobre una amplia gama de usos diferentes, más allá de la transferencia locativa prototípica. Poner aparece con frecuencia, y aún más frecuentemente que $p \hat{o} r$, en el uso predicativo. Sin embargo, pôr aparece con más frecuencia que poner como auxiliar incoativo/causativo. Así, la distancia entre ambos verbos quizás sea menos grande que la que parece existir entre meter $_{\text {esp }}$ y meter $_{p t g}$.

La mayor gramaticalización de los verbos españoles en comparación con sus equivalentes en portugués no debe sorprender: varios estudios tipológicos recientes sobre las lenguas romances han demostrado que el portugués presenta menor gramaticalización comparado al español, por ejemplo en el dominio de los verbos causativos, de los verbos perceptivos y de las preposiciones (cf. De Mulder \& Lamiroy 2008, Enghels \& Roegiest en prensa, Fagard \& Mardale 2012, Soares Da Silva 2012).

\section{Referencias}

\section{Corpus}

\section{(A) Corpus paralelo}

Rowling, Joanne Kate, Harry Potter and the philosopher's stone, London, Bloomsbury, 1997. 
[HPPF-ESP] Dellepiane, Alicia, Harry Potter y la piedra filosofal, Barcelona, Emecé Editores S.A., 1999.

[HPPF-PTG] Fraga, Isabel, Harry Potter e a pedra filosofal, Lisboa, Presença, 1999. Rowling, Joanne Kate, Harry Potter and the chamber of secrets, London, Bloomsbury, 1998.

[HPCS-ESP] Muñoz García, Adolfo/Martín Azofra, Nieves, Harry Potter y la cámara secreta, Barcelona, Emecé Editores S.A., 1999.

[HPCS-PTG] Fraga, Isabel, Harry Potter e a câmara secreta, Lisboa, Presença, 2000.

Rowling, Joanne Kate, Harry Potter and the prisoner of Azkaban, London, Bloomsbury, 1999.

[HPPA-ESP] Muñoz García, Adolfo/Martín Azofra, Nieves, Harry Potter y el prisionero de Azkaban, Barcelona, Emecé Editores S.A., 2000.

[HPPA-PTG] Fraga, Isabel, Harry Potter e o prisioneiro de Azkaban, Lisboa, Presença, 2000.

Rowling, Joanne Kate, Harry Potter and the goblet of fire, London, Bloomsbury, 2000.

[HPCF-ESP] Muñoz García, Adolfo/Martín Azofra, Nieves, Harry Potter y el cáliz de fuego, Barcelona, Salamandra, 2001.

[HPCF-PTG] Fraga, Isabel/Madureira Manuela/Nunes, Isabel, Harry Potter e o cálice de fogo, Lisboa, Presença, 2000.

Rowling, Joanne Kate, Harry Potter and the order of the phoenix, London, Bloomsbury, 2003.

[HPOF-ESP] Rovira Ortega, Gemma, Harry Potter y la orden del fénix, Barcelona, Salamandra, 2004.

[HPOF-PTG] Fraga, Isabel/Madureira Manuela/Nunes, Isabel, Harry Potter e a ordem da fénix, Lisboa, Presença, 2003.

Rowling, Joanne Kate, Harry Potter and the half-blood prince, London, Bloomsbury, 2005.

[HPMP-ESP] Rovira Ortega, Gemma, Harry Potter y el misterio del príncipe, Barcelona, Salamandra, 2006.

[HPPM-PTG] Carmo Figueira, Maria, do et al., Harry Potter e o príncipe misterioso, Lisboa, Presença, 2005.

Rowling, Joanne Kate, Harry Potter and the deathly hallows, London, Bloomsbury, 2007.

[HPRM-ESP] Rovira Ortega, Gemma, Harry Potter y las reliquias de la muerte, Barcelona, Salamandra, 2008.

[HPRM-PTG] Carmo Figueira, Maria, do et al., Harry Potter e os talismãs da morte, Lisboa, Presença, 2007.

(B) Corpus comparable: bancos de datos y novelas

Bessa-Luis, Agustina, A Sibila, Lisboa, Guimarães, 1954.

Bessa-Luis, Agustina, Os espaços em branco, Lisboa, Guimarães, 2003.

CRPC: Corpus de referência do português contemporáneo.

(http://alfclul.clul.ul.pt/CQPweb/crpcweb23/index.php)

El País 1997, 1998, 2002, 2003, 2004.

Jorge, Lidia, O dia dos prodígios, Lisboa, Dom Quixote, 1980.

Jorge, Lidia, Combateremos a sombra, Lisboa, Dom Quixote, 2007.

Lobo Antunes, Antonio, Exortação aos Crocodilos, Lisboa, Dom Quixote, 1999. 
O Público (2008/09/11-2008/10/11.

Pinheiro Torres, Alexandre, A Nau de Quixibá, Lisboa, Caminho, 1989.

Real Academia Española: Banco de datos (CREA: Corpus de referencia del español actual. (http://corpus.rae.es/creanet.html)

Saramago, Jose, O evangelho segundo Jesus Cristo, Lisboa, Caminho, 1991.

Saramago, Jose, Ensaio sobre a Lucidez, Lisboa, Caminho, 2004.

Sousa Tavares, Miguel, Equador, Cruz Quebrada/Dafundo, Lisboa, Oficina do livro, 2003.

Vale Ferraz, Carlos, Flamingos dourados, Lisboa, Noticias, 2004.

\section{Obras citadas}

Academia das Ciências de Lisboa, Dicionário da Língua Portugueas Contemporânea da Academia das Ciências de Lisboa, Lisboa, Verbo, 2001. [DLP]

Aijmer, Karin/Altenberg, Bengt/Johansson, Mats, Languages in Contrast. Papers from a Symposium on Text-based Cross-linguistic Studies. Lund 4-5 March 1994, Lund, Lund University Press, 1996.

Alarcos Llorach, Emilio, La noción de suplemento, Logroño, Gobierno de la Rioja, Consejería de Educación, Cultura y Deportes, 1990.

Altenberg, Bengt/Granger, Sylviane, Lexis in contrast. Corpus-based approaches, Amsterdam, John Benjamins Publishing Company, 2002.

Boons, Jean-Paul, La notion sémantique de déplacement dans une classification syntaxique des verbes locatifs, Langue française 76 (1987), 5-40.

Cifuentes Honrubia, José Luis, Sobre las construcciones locales en español, in: Cifuentes Honrubia J.L. (ed.), Estudios de Lingüística, Alicante, Universidad de Alicante, 1988-89, vol. $5,145-181$.

Cifuentes Honrubia, José Luis, Verbos locales estativos en español, in: Cifuentes Honrubia, José Luis /Marimón Llorca C. (edd.), Estudios de Lingüística: el verbo, Alicante, Universidad de Alicante, 2004, 73-118.

Cifuentes Honrubia, José Luis/Llopis Ganga, Jesús, Complemento indirecto y complemento de lugar: Estructuras locales de base personal en español, Alicante, Universidad de Alicante, 1996.

Cifuentes Honrubia, José Luis/Llopis Ganga, Jesús, Sobre la semántica de los verbos de desplazamiento y su tipología, in: Oliver Frade, J.M. et al. (edd.), Cien años de investigación semántica: de Michel Bréal a la actualidad, Madrid, Ediciones clásicas, 2000, 319-332.

Corominas, Joan, Breve diccionario etimológico de la lengua castellana, Madrid, Gredos, 1987.

Crego García, María Victorina, El complemento locativo en español. Los verbos de movimiento y su combinatoria sintáctico-semántica, Santiago de Compostela, Universidade de Santiago de Compostela, 2000.

Cuartero Otal, Juan, Cosas que se hacen. Esquemas sintáctico-semánticos agentivos del español, Frankfurt am Main, Peter Lang GmbH, 2003.

Cuenca, Maria Josep/Hilferty, Joseph, La gramaticalización, in: Cuenca, Maria Josep/Hilferty, Joseph (edd.), Introducción a la lingüística cognitiva, Barcelona, Editorial Ariel S.A, 1999, 151-178. 
Divjak, Dagmar, Structuring the Lexicon: a Clustered Model for Near-Synonymy, Berlin New York, Mouton de Gruyter, 2010.

Cuervo, Rufino José, Diccionario de construcción y régimen de la lengua castellana, Barcelona, Herder, 2002. [CD-ROM] [DCR]

De Mulder, Walter/Lamiroy, Béatrice, Different stages of grammaticalization: The position of French among the Romance languages. Paper presented at the 4th International Conference "New Reflections on Grammaticalization", University of Leuven, 16-19 July 2008.

Dixon, Robert, A new approach to English grammar. On semantic principles, Oxford, Clarendon Press, 1991.

Enghels, Renata/Jansegers, Marlies, On the cross-linguistic equivalence of sentir(e) in Romance languages: a contrastive study in semantics, Linguistics 51:5 (2013), 957-991.

Enghels, Renata/Roegiest, Eugeen, en prensa. Contrasting the syntax and semantics of negative causation. The apparent similarity of Spanish and Portuguese. Languages in Contrast.

Fagard, Benjamin/Mardale, Alexandru, The pace of grammaticalization and the evolution of prepositional systems: Data from Romance, Folia Linguistica 46 (2012), 303-340.

Garachana Camarero, Mar, Los procesos de gramaticalización, Moenia 5 (1999), 155-172.

Geeraerts, Dirk, 2010, Theories of Lexical Semantics, Oxford, Oxford University Press.

Gellerstam, Martin, Translations as a source for cross-linguistic studies, in: Aijmer, Karin/Altenberg, Bengt/Johansson, Mats (edd.), Languages in Contrast. Papers from a Symposium on Text-based Cross-linguistic Studies. Lund 4-5 March 1994, Lund, Lund University Press, 1996, 54-62.

Guillet, Alain/Leclère, Christian, La structure des phrases simples en français 2: Constructions transitives locatives, Genève-Paris, Droz, 1992.

Houaiss, Antônio, Dicionário Houaiss da Língua Portuguesa, Lisboa, Círculo de Leitores, 2003. [DH]

Kleiber, Georges, La sémantique du prototype: catégories et sens lexical, Paris, PUF, 1990.

Lamiroy, Béatrice, Léxico y gramática del español. Estructuras verbales de espacio y tiempo, Barcelona, Anthropos, 1999.

Lehmann, Christian, A auxiliarização de ficar, in: Maria Clotilde, Almeida/Bernd Sieberg/Ana Maria Bernardo (eds.), Questions of language change, Lisboa, Colibri, 2008, 9-26.

Levin, Beth, English verb classes and alternations: a preliminary investigation, Chicago, Chicago University of Chicago Press, 1993.

Maldonado, Claudio, Clave: diccionario de uso del español actual, Madrid, Ediciones SM, 1996. [CL]

Moliner, María, Diccionario de uso del español, Madrid, Gredos, 2007. [DUE]

Morais Silva, António, de, Grande Dicionário da Língua Portuguesa, Lisboa, Editorial Confluência, 1945. [GDLP]

Noël, Dirk, Translations as evidence for semantics: an illustration, Linguistics 41 (2003), 757-785.

Real Academia Española, Nueva gramática de la lengua española, Madrid, Espasa Libros, 2009. 
Rodríguez-Piñero Alcalá, Ana Isabel, La parasinonimia como relación léxica, Pragmalinguiística 12 (2004), 105-121.

Rojo, Guillermo, En torno a los complementos circunstanciales, in: s.n. (ed.): Lecciones del I y II Curso de Lingüística funcional (1983 y 1984), Oviedo, Universidad de Oviedo, 1985, 181-190.

Salkie, Raphael, How can linguists profit from parallel corpora, in: Borin Lars (ed.), Parallel corpora, parallel worlds, Amsterdam, Rodopi, 2002, 93-109.

Seco, Manuel/Andrés Puente, Olimpia/Gabino Ramos, González, Diccionario del español actual, Madrid, Aguilar, 1999. [DEA]

Slobin, Dan, Two ways to travel: Verbs of motion in English and Spanish, in: Shibatani, Masayoshi/Thompson, Sandra (edd.), Grammatical Constructions. Their Form and Meaning, Oxford, Clarendon Press, 1996, 195-219.

Soares Da Silva, Augusto, Stages of grammaticalization of causative verbs and constructions in Portuguese, Spanish, French and Italian, Folia Linguistica 46/2 (2012), 513-552.

Talmy, Leonard, Lexicalization patterns: semantic structure in lexical forms, in: Shopen, Timothy (ed.), Language typology and syntactic descriptions, New York, Cambridge University Press, 1985, 57-149.

Talmy, Leonard, Path to Realization: A Typology of Event Conflation, Proceedings of the Seventeenth Annual Meeting of the Berkeley Linguistics Society 17 (1991), 480-519.

Vanderschueren, Clara, The use of translations in linguistic argumentation. A case study on Spanish and Portuguese subordinate clauses introduced by para, Languages in Contrast 10 (2010), 76-101.

Van Hoecke, Willy/Goyens, Michble, Translation as a witness to semantic change, Belgian Journal of Linguistics 5 (1990), 109-131.

Van Gorp, Lise, Ponerse como pseudo-cópula: una manera específica de concebir el cambio en español, in: Cabedo Nebot, Adrián/Infante Ríos Patricia (edd.), Lingüística XL. El lingüista del siglo XXI, Madrid, SeL Ediciones, 2012, 395-401. 